\title{
к. ГАЛИНСКИ
}

\author{
Галински Карл (Galinsky Karl) \\ $P h D$ \\ npoøbeccop (Cailloux Centennial Professor), \\ кафедра классической фбллологии, \\ Техасский университет в Остине (США) \\ 110 Inner Campus Drive, Austin, TX 78705, USA \\ Тел.: +1 (512) 471-85-04, +1 (512) 471-57-42 \\ E-mail: galinsky@austin.utexas.edu
}

\section{АВГУСТОВСКАЯ ЛИТЕРАТУРА И АВГУСТОВСКАЯ «ИДЕОЛОГИЯ»: ПЕРЕСМОТР ОЦЕНОК ${ }^{1}$}

\begin{abstract}
Аннотация. Для исследований отношений между литературой и политикой в античности одним из центральных объектов внимания традиционно является августовский период, особенно отношения между Августом и поэтами. В статье рассматриваются важнейшие тенденщии изменяющихся оценок соответствующего периода с древности до нашего времени, а также причины этих оценок. Я следую за фрундаментальным тезисом Питера Уайта, что «политическая» интерпретация августовской поэзии - это анахронистическая проекция. Затем я кратко разбираю, чем неточно понятие «идеология». Анализируя некоторые репрезентативные примеры, такие как Hor. Carm. 1.2, я вырабатываю более релевантную концепцию охватывающего всю нацию дискурса или дискуссии, в которой, помимо Августа, есть еще много участников с множеством различных перспектив. В то время как предложенная Р. Саймом модель «организации общественного мнения» в целом была отвергнута наукой, бинарные оппозищии оказались слишком упрощенным инструментом и все больше уступают место более динамическим подходам, которые также лучше учитывают реалии эпохи, в том числе намеренную многозначность произведений искусства. Еще одной интерпретативной проблемой, на которую вновь обратили внимание исследования культурной и исторической памяти, является проецирование настоящего на прошлое.
\end{abstract}

Ключевые слова: августовская литература, политика и литература, идеология, презентизм, подводные камни интерпретации, Тиберий Клавдий Донат, Августовский век, многозначность, Гораций, Вергилий, Ливий, Овидий

${ }^{1}$ Статья представляет собой несколько расширенный текст доклада, сделанного на Гаспаровских чтениях в Москве в апреле 2017 г. Я счастлив поблагодарить профессора Н. П. Гринцера за приглашение и всех причастных к организации конференции за внимание и гостеприимство, а также других участников конференции за вопросы и комментарии. 
Д

ля изучения отношений между литературой и политикой в античности одним из центральных объектов внимания традиционно является августовский период, особенно отношения между Августом и поэтами. Ответы на вопрос о природе этих отношений бывают очень разными и охватывают весь спектр от сервильной покорности до независимости и подрывной деятельности поэтов ${ }^{2}$. Бросается в глаза, что (как часто бывает в такого рода исследованиях) эти оценки говорят нам не меньше (а иногда даже больше) о ментальности и культурном и политическом бэкграунде интерпретаторов, чем о реальных обстоятельствах и условиях эпохи Августа. Мы неизбежно подходим к таким темам с нашим собственным обусловленным временем представлением о мире, с нашей собственной перспективой и даже с собственным опытом. Не стоит смотреть на это как на чистый релятивизм; по сути дела, то, что мы (а под словом «мы» я имею в виду наблюдателей и ученых с древности до нашего времени) можем смотреть на эти явления по-разному, - это как раз здоровая ситуация. Одна из причин такого положения дел заключается в том, что любой аспект августовской эпохи - будь то изобразительное искусство, социальная история, религия или литература - всегда имеет несколько измерений; даже Тацит признавал это в своем знаменитом суждении об Августе в «Анналах» 1.9 и $1.10^{3}$.

Другой фактор, который был хорошо акцентирован в недавних исследованиях исторической памяти, - это то общее место, что мы часто (иногда слишком часто) воспринимаем прошлое в терминах современности ${ }^{4}$ Из совокупности этих факторов и вытекает та интересная динамика, которая возникает, когда мы пытаемся выяснить роль августовской литературы в политическом контексте своего времени. И более того (последняя вещь, которую я хочу отметить во введении), эти оценки совсем не статичны, а, наоборот, всегда находились в движении. На мой взгляд, это положительная черта, и только такой подход и уместен в случае с эпохой Августа, которая и сама устроена так же: это был совсем не статический золотой век, начавшийся на следующее утро после битвы при Акции, а непрерывно продолжавшийся процесс работы - это одна из важных причин живучести его достижений, - и писатели были составной частью этого процесса. Они отвечали на это новое явление по-разному — никакого единообразия реакций не было - и участвовали в придании ему формы.

2 Удобный обзор работ, опубликованных до 1975 г., см. в [Little 1982] с полезными списками работ по отдельным авторам и произведениям на с. 350-370. См. более свежие обсуждения в [Woodman, West 1984], некоторые главы в [Raaflaub, Toher 1990], главы, написанные В. Штро, в [von den Hoff et al. 2014].

${ }^{3}$ Выдающийся пример целенаправленной многозначности - это «Деяния божественного Августа», как в целом, так и на уровне отдельных фраз и пассажей; см. издания и комментарии: [Scheid 2007; Cooley 2009]. О полисемии и богатстве ассоциаций в августовском изобразительном искусстве см.: [Zanker 1987], а также [Torelli 1992], особенно c. 39-43, и [Galinsky 1992] о конкретном случае Алтаря Мира. В архитектуре парадигматичен Мавзолей Августа, как в литературе - вергилиевская Дидона, см. обзор в [Galinsky 2012: 154-158].

${ }^{4}$ Репрезентативные примеры из весьма обширной литературы: [Assman 2007], многие статьи в [Pethes, Ruchatz 2001], отдельные очерки в [Erll, Nünning 2010]. Примеры работ о Риме: [Gowing 2005; 2016; Galinsky 2016a]. 
Для контраста, а также чтобы у нашей дискуссии были некие точки, от которых она могла бы отталкиваться, я вкратце скажу о более статическом образе этой эпохи, на протяжении некоторого времени доминировавшем в обсуждении нашей темы. Суть этих представлений была, конечно, в том, что августовские писатели просто возносили хвалы новому порядку и прославляли юлиевский режим. У Тиберия Клавдия Доната (конец IV - начало V в. н. э.) мы находим компактную формулировку этой идеи в рамках изложения raison d’être «Энеиды» Вергилия [Georgii 1905-1906 (1): 2-3]:

[Vergilius] talem enim Aeneam monstrare debuit, ut dignus Caesari, in cuius honorem haec scribebantur, parens et auctor generis praeberetur.

Ведь Вергилий должен был представить Энея таким, чтобы он оказался достойным прародителем и основателем рода для Августа, в честь которого «Энеида» была написана.

Этот взгляд, конечно, разделяли английские и французские «августовцы». Он был поддержан (пусть полемически) такими знаменитостями XX в., как Роберт Грейвз («Культ Вергилия» [Graves 1962]) и, еще более влиятельным образом, Рональд Сайм. Последний, со своими широкой кистью и острым пером, применяет эту модель к Вергилию и Горацию в главе «Организация общественного мнения» своей книги «Римская революция» [Syme 1939: 459475]. Схема проста: эти поэты были рупорами режима - в отличие от Овидия, который был «позорищем» и которого необходимо было удалить, - они были пропагандистами. Сайм, однако, недвусмысленно давал понять, что пишет книгу в контексте своего времени - конца 1930-х годов, т. е. именно во время европейских диктаторов, которые, подобно Августу, оказывавшемуся в проекции Сайма их крестным отцом, захватили власть в результате разного рода насилия. Концепция центрально координируемой пропаганды имела поэтому большой резонанс. Приведу лишь один пример, не связанный с литературой: эта концепция сильно повлияла на представление о римских монетах, с которым ученые спорят до сих пор: очень важные каталоги римских монет Британского музея опубликованы именно в это время, и на августовские монеты в особенности быстро стали смотреть как на инструмент пропаганды ${ }^{5}$.

Но вернемся к августовской литературе. После характеристики, предложенной Саймом, и попыток Муссолини присвоить своей идеологии римскую классику, прежде всего национальный эпос Вергилия, ученые, смотревшие с симпатией на Вергилия и Горация, взялись реабилитировать их, показывая, что эти поэты на самом деле относились к августовскому режиму скептически. Объектом поиска, таким образом, стали двусмысленности (которые всег-

${ }^{5}$ Показателен общий заголовок написанного В. Трилльмихом раздела о нумизматике в каталоге берлинской выставки «Цезарь Август и потерянная республика» (1988): «Монетная пропаганда» [Trillmich 1988: 474-491]. Как и другие понятия такого рода (см. ниже об «идеологии»), понятие «пропаганда» не следует употреблять как нечто само собой разумеющееся: см. мои краткие замечания в [Galinsky 1996: 40-41] со ссылками на работы Жака Эллюля и др. Очень типично, например, что в книге [Powell 1992] слово «пропаганда» включено в название, при этом в тематическом указателе его нет и никакого обсуждения современных исследований этой темы в книгу не включено. 
да легко находятся, если учесть многозначность латинских слов) с акцентом на диссидентских смыслах. Главным аргументом стал конец «Энеиды»; там, как показывали ученые, Эней поддается ярости и гневу, уподобляющим его Юноне, а значит, как Майкл Патнем интерпретировал это в 1963 г. (и не уставал вновь и вновь повторять после этого), «по замыслу поэта, именно она [т. е. мстительная Юнона], а не Эней и не то величие, которое, как кажется, ассоциируется с Августом, одерживает величайшую победу» в конце поэмы [Putnam 1965: 201]. Этот тезис с разными дополнениями впоследствии доминировал в дискуссиях на протяжении нескольких десятилетий, в особенности в Америке. Обратите внимание на смешение «величия Августа» с перипетиями поведения Энея: упрощенная традиционная схема Тиберия Клавдия Доната была не отвергнута, а просто перевернута с ног на голову.

Мораль этой истории, на мой взгляд, такова: для научного прогресса недостаточно просто отреагировать на доминирующую интерпретацию, заменив тезис на антитезу. Так далеко не уйдешь. В какой-то степени это та самая проблема, с которой сталкиваются магистранты и аспиранты, когда увлекаются длинными докладами по истории вопроса на исследовательских семинарах для начинающих: разумеется, нужно знать, что писали предшественники, но нельзя ограничиваться лишь этим. В данном случае, таким образом, вместо того чтобы отвоевывать новые территории (если это вообе отвоевывание) внутри дихотомий вроде «проавгустовское vs антиавгустовское» (сp. [Kennedy 1992]), гораздо полезнее вернуться, так сказать, к часу творения и посмотреть на реальный исторический контекст августовских писателей и на те вопросы, на которые они отвечали, одновременно задавая само направление дискуссий о них.

Важная проблема очевидным образом заключается в том, чтобы найти подход к прошлому в тот момент, когда будущее даже близко не было таким определенным, каким оно стало для глядящих назад нас. Ключевой пример здесь - «Энеида», и невозможно преувеличить важность следующего тезиса: она не была продуктом прекрасного в своей опрятности монолитного возрождения «золотого века». Она была написана в 20-е годы до н. э., когда, наряду с высокой оценкой стабильности, оставалось еще очень много неопределенности, тревог, скорбей и чисто материальных кризисов ${ }^{6}$ как Август будет править? что будет, если с ним что-то случится (он чуть не умер в 23 г. до н. э.)? действительно ли гражданские войны на этом закончатся, учитывая, что вокруг полмиллиона солдат, привыкших сражаться в этих самых гражданских войнах? Все еще продолжались трудности с продовольствием и с выходами Тибра из берегов, на востоке в дверь стучались парфяне. В этом, если говорить коротко, и была одна из причин той множественности голосов, которую отмечали в этом эпосе 7 . Главная интонация поэмы - это интонация не триумфа, а продолжающихся усилий и осторожной надежды. С точки зрения методологии идея, что любое великое произведение литературы вызовет разные читательские отклики и благодаря этому окажется живучим в людской памяти,

${ }^{6}$ Одна из немногих недавних работ, где подчеркивается этот аспект, — [Schauer 2007].

${ }^{7}$ В новейшей истории интерпретации текста Вергилия долгое время была объектом почти что культа статья Адама Пэрри «Два голоса в “Энеиде” Вергилия» [Parry 1963]. Его бинарная модель («публичный» vs «частный» голос) была расширена в последующих интерпретациях (я намеренно не называю их «исследованиями»), таких как [Lyne 1987]. 
конечно, банальна. Всякое великое литературное произведение многозначно и многослойно. Одна из проблем, связанных с интерпретацией конкретно августовской поэзии, заключается в том, что эта многослойность (нем. Vielschichtigkeit — гораздо более точный термин, чем «двусмысленность», ambiguity) ${ }^{8}$ истолковывалась слишком узко через призму политики, как будто поэты старались на каждом шагу сделать по политическому утверждению, а Август был единственным читателем, последней инстанцией и адресатом. На самом деле горизонт был шире - здесь остается полезной терминология Ханса-Роберта Яусcа 9 .

На самом деле неправильно представлять дело таким образом, будто Август в одиночестве думал о наиболее острых проблемах текущего момента, а затем натягивал смирительную рубашку на их литературные воплощения. Вопрос о том, что произошло с Римом и чуть не обрушило его, был предметом дискуссий как для образованных классов, так и для не-элит, хотя от последних, как обычно бывает, до нас не дошло практически никаких литературных свидетельств. Что было причиной страданий, постигших Рим? Литература полна разных ответов и перспектив: вот она, охватывающая нацию дискуссия, это совсем не навязанная государством точка зрения. Палитра мнений включает и вступление Ливия с его заостренными формулировками об упадке mores (нравов) и неисцелимых vitia (пороках), и напоминание Вергилия о первородном грехе клятвопреступления Лаомедонта (Geo. 1.501-502) и братоубийства Ромула (Aen. 1.292-293), и преследующие воспоминания о pulvis Etrusca («этрусском прахе») и funera Italiae («гробах Италии») у Проперция (1.22); Гораций предлагает свое попурри, смешивая жалобы на моральный упадок в духе Ливия в одах 3.6 и 3.24 и Ромула с Ремом в VII эподе, в то время как в оде 3.3 Юнона объявляет обман Лаомедонта троянским прошлым, которое не будет повторено в Риме. И, как обычно, нет никакой установки на последовательность. В других местах Гораций говорит о Ромуле в его божественной ипостаси Квирина, не вспоминая о его человеческом прошлом (Carm. 3.3.1516). В этом случае он уже не является смертным, он - бессмертный предок Августа, и его проступки, таким образом, оказываются аннулированы.

Другой такой пример - Hor. Carm. 1.2.45-49 (см.: [Nisbet, Hubbard 1970: ad loc.]). Я хочу рассмотреть эту оду и саму по себе, и как миниатюрную модель для моего тезиса об обсуждениях и дискуссиях, охватывающих всю нацию. Как Октавиан стал Августом? Главной альтернативой, как свидетельствуют Светоний (Aug. 7.2) и Дион Кассий (53.16.5-7), была на полном серьезе рассматривавшаяся Октавианом идея взять себе имя Ромула. В конце концов он от этой идеи отказался, потому что в ее подтексте явно различалось affectatio regni, «стремление установить царскую власть» (не говоря уже об альтернативной версии, согласно которой Ромул был убит сенаторами), и выбрал вариант «Август»; ассоциативный ореол этого имени был одновременно богаче и

${ }^{8}$ Из-за своей этимологии слово ambiguity ‘двусмысленность’ часто связывается с представлением, что опций всего две, и это не раз приводило к выстраиванию бинарных перспектив. Опять же здесь нужен более аккуратный подход; хорошую стартовую дискуссию см. в [Bahti 1986].

${ }^{9}$ См.: [Jauss 1977], где различаются три базовых «горизонта ожидания». 
не отягощен какими-либо негативными традициями ${ }^{10}$. Само собой, эти решения не были приняты за пару недель до заседания сената в январе 27 г. до н. э., известного как «Первое урегулирование» и ставшего первым шагом к оформлению августовского принципата. В реальности все поднятые там вопросы уже до того были предметом обширных дискуссий, как видно из спора между Меценатом и Агриппой в 52-й книге Диона Кассия или из ауреуса Октавиана, чеканенного на монетном дворе в Азии, с надписью «Он восстановил законы и права» (leges et iura restituit): этот ауреус был выпущен за год до упомянутого заседания сената ${ }^{11}$. Если возвращаться к Горацию, то в оде 1.2 он разбирает разные возможности уподобления божеству для Октавиана. Какому богу, спрашивает Гораций, Юпитер даст задачу искупить scelus (преступление) гражданских войн — cui dabit partis scelus expiandi / Iuppiter? (1.2.29-30). Поэт упоминает несколько вариантов, заканчивая самим Октавианом и желая ему еще долго оставаться среди Квиринова народа. Здесь перед нами, таким образом, гораздо больше, чем просто интертекстуальная отсылка к молитвам Вергилия в конце первой книги «Георгик» (498ff.), особенно учитывая, что далее Гораций называет Октавиана pater atque princeps «отцом и принцепсом». Опять же наиболее вероятная дата для этой оды — за год или два до 27 г. до н. э., когда эти термины, ставшие позднее официальными, уже были предметом обсуждений. Гораций явно зависим от этой дискуссии ${ }^{12}$.

То же самое, я полагаю, относится и к восприятию Горацием Октавиана как уже обожествленного, divus: serus in caelum redeas «возвращайся на небеса попозже» (1.2.45). Гораций, Вергилий и Овидий говорят об Августе как о боге во многих местах, и, как рассудительно указывают Нисбет и Хаббард, это не просто поэтическая вольность или бессовестная лесть: это отражает «то, что происходило в реальном мире» [Nisbet, Hubbard 1970: 20]. Конечно, это правда, что Август всегда был против культового почитания себя внутри города Рима и что мы сталкиваемся с распространением разных форм императорского культа в Италии (достаточно добраться уже до Остии) и в провинциях только после 27 г. до н. э. ${ }^{13}$ Но, опять же, очевидно, что эта тема обсуждалась на протяжении многих лет уже до того. Она была частью дискуссии общенационального масштаба, и именно на такую дискуссию опирается Гораций.

Число примеров можно увеличить, и у разных поэтов они устроены поразному, но перейдем к самому вопросу о политической интерпретации августовской поэзии. Я могу быть здесь относительно краток, потому что по

10 Типичным для себя образом он тем не менее не отказался от ассоциаций с Ромулом. Работа [Gagé 1930], хотя в некоторых отношениях устаревшая, остается обязательной для прочтения по этому вопросу; краткие обновляющие дополнения см. в [Galinsky 2013: 3236]. Как отмечал Светоний (Aug. 7.2), слово augustus было ассоциативно связано с Ромулом благодаря знаменитой строке Энния - augusto augurio postquam inclita condita Roma est «После того как на основе священных (augustum) гаданий по птицам был основан славный Рим» (Enn. Ann. 155 Skutsch); см. наиболее свежую работу: [Wardle 2014: 107-108].

${ }^{11}$ Британский музей, Department of Coins and Medals CM 1995,0401.1. Комментарий экспертов см. в [Rich, Williams 1999].

${ }_{12}$ В «Деяниях божественного Августа» Август говорит о себе как о princeps'е уже в связи с 35-34 гг. до н. э. (в главе 30) и с 29 г. до н. э. (в главе 13): обсуждение явно было длительным. Этот титул никогда не был формализован, в то время как титул pater patriae «отец отечества» был во 2 г. до н. э. См.: [Nisbet, Hubbard 1970: 38-39; Cooley 2009: 161].

${ }^{13}$ См. краткий обзор в [Beard et al. 1998 (1): 348-363]. 
этой теме существует фундаментальная книга Питера Уайта [White 1993]. Как показал Уайт, такая интерпретация восходит к «Трактату об эпической поэме» (в шести книгах) французского аббата Рене Ле Боссю, жившего при Людовике XIV. Основной его темой были la politique и instruction politique, под которыми он понимал в основном гражданское или моральное воспитание (вспомним аристотелевское zoon politikon). «Он никогда не применяет слово politique к политическим программам или практическим вопросам государственного управления» [Ibid.: 102]. Однако когда этот труд был переведен на английский, слово politique поменяло значение в контексте политических споров, в которые были вовлечены многие выдающиеся писатели ${ }^{14}$. Теперь оно подразумевало занятие политической позиции и выступление за какуюто политическую программу. Ко времени выполненного Джоном Драйденом в 1697 г. эпохального перевода «Энеиды» и сопровождавшего перевод вступительного очерка уже была сформулирована точка зрения, согласно которой «августовское поэтическое произведение пропагандирует внушенное государством сообщение о практическом вопросе политики» [Ibid.: 107], изначально применительно к «Георгикам». Дальше открывался простор для применения этого подхода к другим поэтическим текстам. Крайне влиятельной фигурой был Анри Патен, профессор латинской поэзии в Сорбонне в начале XIX в. Он решительно заявил, что в ю поэзию, написанную при Августе, следовало интерпретировать как политическую, потому что Август сделал поэтов своими политическими агентами. Всего через несколько десятилетий этот взгляд был принят «Encyclopedia Britannica» и очень авторитетной «Историей римской литературы» Тойффеля, а в конце концов и Рональдом Саймом.

Разумеется, это очень упрощенная точка зрения, и в целом ее уже никто не придерживается. Она, конечно, непосредственно связана с тем, как мы понимаем слово «политический», и здесь мы можем вновь обратиться к аристотелевскому, додрайденовскому значению слова, подразумевающему «гражданскую вовлеченность». Именно о ней следует говорить применительно к августовским писателям: их тексты ни в коем случае не изолированы от повестки дня, но в то же время не являются манифестами какой-то политической позиции, несмотря даже на то, что некоторые из этих писателей были атісі Августа. Я вернусь к этим перспективам через некоторое время, но сперва я бы хотел обратиться к одному родственному современному понятию, применявшемуся к августовской тематике. Я говорю об идеологии.

Рожденное в ходе Французской революции, полемически использовавшееся Наполеоном против парижской группы, называвшей себя «идеологами», и подробно разработанное Мишелем Фуко и современной политической теорией, понятие «идеология» стало часто употребляемым обозначением для любого комплекса убеждений, которых придерживаются отдельные люди, группы людей или руководства стран ${ }^{15}$. В таком более широком смысле это понятие безусловно применимо к правлению Августа. В то же время сегодня этот термин приобрел коннотации, которые можно назвать, в зависимости от

${ }^{14}$ Хороший очерк этой ситуации см. в [Weinbrot 1978].

${ }^{15} \mathrm{C}$. хорошо документированную статью англоязычной Википедии (https:// en.wikipedia.org/wiki/Ideology), где также есть хорошая библиография. Ср. источники, цитируемые мной в [Galinsky 1996: 404, n. 1]. 
отношения к ним, более точными или более ограничивающими. Они включают навязывание нормативного поведения, отсутствие гибкости, претензию на единоличное обладание истиной, некоторую узость взгляда, мышление в терминах идентичности ${ }^{16}$ и систематическое теоретизирование. Как и в случае с «политическим», таким образом, трактовка зависит от того, какую точку мы выберем в семантическом спектре. Я всегда старался избегать того, чтобы видеть в «идеологии» общий знаменатель деятельности Августа, потому что он не был идеологом в современном смысле слова и было бы неосторожно поставить его в один ряд с современными идеологами, как правыми, так и левыми. В отличие от них, он был гораздо более прагматичен, гибок и готов к экспериментам ${ }^{17}$. Разумеется, им руководил некий набор ценностей, но это были не только его ценности.

Они сформулированы, к примеру, в ливиевском вступлении (1.pr.9); Ливий говорит о возведении памятника нравам (mores) и жизням мужей, «искусствами» (artes) которых в гражданской и военной области была создана и расширена держава (imperium):

ad illa mihi pro se quisque acriter intendat animum, quae vita, qui mo res fuerint, per quos viros quibusque artibus domi militiaeque et partum et auctum imperium sit.

Пусть у меня каждый по мере своих сил направит свое внимание на то, какова была жизнь, каковы нравы (mores), благодаря каким мужам и какими искусствами (artibus) во внутренних делах и во внешних войнах держава (imperium) была и рождена, и увеличена.

Отмечу два момента. Во-первых, в знаменитом своей краткостью описании римского национального характера в «Энеиде» Вергилий пользуется теми же самыми терминами (6.851-852):

tu regere imperio populos, Romane, memento, hae tibi erunt artes, pacique imponere morem...

Ты же, римлянин, помни править над народами своей державой (imperio) - это будет твое искусство (artes) — и налагать на мирное состояние добронравие (morem)...

Перед нами, таким образом, еще один конкретный пример имевшего место диалога, дискуссии. Кроме того, как отмечал Норден, слово debellare в следующей вергилиевской строке относится к любимым у Ливия [Norden 1970: 338]; можно добавить к этому, что выбор Вергилием слова memento 'помни', кроме того что подкрепляет постоянно присутствующую в «Энеиде» тему памяти ${ }^{18}$, еще и соответствует столь же постоянному присутствию этой темы в прологе Ливия: rerum gestarum memoriae «памяти о деяниях» (1.pr.3), rerum

${ }^{16}$ Один из аспектов, акцентируемых в [Eagleton 1994].

${ }^{17}$ О некоторых из этих аспектов см.: [Galinsky 1996: 80-140].

${ }^{18}$ Тон задается выбором слова тетоra 'извлеки из памяти' в Вергилиевом обращении к Музе (1.8, ср. 7.41 и 7.645). См.: [Seider 2013] и краткий обзор в [Galinsky 2016b: 7-10]. 
gestarum monumentis «памятниками деяний» (1.pr.6), documenta in inlustri posita monumento «поучения, помещенные в светлом памятнике» (1.pr.10) (cp. [Jaeger 1997: 20-21]).

Во-вторых, чтобы мы не думали, что речь шла просто о следовании «линии Августа», один из многочисленных случаев ливиевской независимости - это его отступление от выбора Августа при увековечивании этих великих римлян, summi viri, на Форуме Августа. Как показал Джеймс Льюс, есть множество расхождений между похвалами (elogia) этих мужей на Форуме Августа и той информацией о них и теми акцентами в их характеристиках, которые мы находим у Ливия [Luce 1990].

Говоря без обиняков, перед нами ситуация разделяемых и обсуждаемых общих ценностей, но различающихся перспектив и литературных воплощений. Этого и следовало ожидать, если только не исходить из предпосылки о Gleichshaltung («насильственной унификации»): материал, с которым работали писатели, включая и самого Августа, вовсе не был единообразным или одномерным, у него было много измерений, провоцировавших множественные ответы и литературные интерпретации. Я закончу статью тем, что вкратце выделю по одному такому аспекту для Вергилия, Горация и Овидия и затем поставлю финальный вопрос.

Суть моей позиции в следующем. Как и в случае с «Историей» Ливия, если бы Август сам написал «Энеиду», «Оды» Горация или «Метаморфозы» Овидия, они были бы совсем другими текстами, и не только в качественном отношении. Важнейший тезис, касающийся «Энеиды», заключается в том, что у Вергилия были альтернативы. Вергилий не обязан был писать «Энеиду». Исходя из традиций римского эпоса и из вступления к третьей книге «Георгик», скорее следовало бы ожидать, что он напишет эпическую поэму об Октавиане ${ }^{19}$. Предметом была бы кульминация римской истории с парой флешбэков о судьбе троянского предка, интонация по необходимости была бы более триумфальной и панегирической, а общий характер эпоса был бы совсем иным. Вергилий перевернул эту модель: мы смотрим на Рим с точки зрения его прародителя; Рим в «Энеиде» вообще еще не основан, биография Рима и его достижения только создаются в процессе непрерывной работы, параллельно прямо на наших глазах (ре)конструируется римская культурная память, и т. д. Август появляется всего три раза; в остальном эпос о том, какие великие усилия (tanta moles) потребовались, чтобы «дать начало римскому роду» (Romanam condere gentem - 1.33). Становится ли из-за этого текст менее августовским? Вовсе нет; мы можем вновь обратиться к summi viri Форума Августа, на сей раз для того, чтобы отметить сходства. Август сознательно поставил несколько пьедесталов для будущ их summi viri, чтобы показать, что этот процесс не прекращается; и мы знаем, что такие статуи позднее действительно там ставились (Dio 55.10.3 с комментарием [Swan 2004: 97; Geiger 2008]). Кроме того, Вергилий универсализировал римский и августовский опыт, сделав из него парадигму человеческого опыта вообще; традиционный военный эпос об Августе никогда бы не поднялся до такого уровня. И, конечно, такой эпос был бы несколько более проблематичным, учитывая эксцессы

${ }^{19}$ См., например, краткое обсуждение в работе [Thomas 1988: 36-37]. 
триумвирата и по сути дела гражданской войны против Антония. Эней не нес с собой ничего, кроме своего отца; Октавиан нес с собой гораздо больше.

Что касается Горация, то по его лирической поэзии особенно хорошо видно, что было бы неправильно придавать слишком большое значение политическому измерению его отношений с Августом. Конечно, есть оды об Августе, например 1.2, 1.12 и 4.15, и есть так называемые «Римские оды» (3.1-6), в которых речь идет о разных римских ценностях. Однако подавляющая часть од - это поэзия на случай, посвященная таким темам, как дружба, вино, любовь, смена времен года, безмятежность духа, неизбежность смерти и т. д. В основном оды можно назвать «поэзией стиля жизни»: выделяются такие предметы, как otium, соблюдение меры во всем и, конечно, поэтическое бессмертие. Показательна ода 3.29 с обращенным к Меценату приглашением на время передохнуть от мира государственных дел и присоединиться к Горацию в Тибуре; центральным в стихотворении является мотив carpe diem («пользуйся сегодняшним днем» $)^{20}$. И это была не просто поэзия: мы знаем из переписки между Августом и Горацием, цитируемой Светонием, что Август хотел сделать Горация своим личным секретарем (Vita Hor. 18-25). Гораций отказался, но это никак ему не повредило: Август продолжал писать ему письма все в том же добродушно-шутливом тоне (судя по светониевскому жизнеописанию Горация). Это один из самых сильных аргументов в пользу предлагаемого Питером Уайтом пересмотра природы отношений между Августом и поэтами в терминах amicitia, дружбы ${ }^{21}$. В римском контексте это слово подразумевало не просто приятельство (вспомним вполне официальную процедуру, когда император, например Тиберий, amicitiam renuntiat «отвергает дружбу»), но все же и не просто политическую лояльность ${ }^{22}$. Говоря коротко, amicitia - более нюансированное и аккуратное обозначение для отношений между Августом, Меценатом и прочими, с одной стороны, и literati, «образованными людьми», с другой, чем расплывчатый «патронаж», часто подразумевающий ренессансную модель.

Наконец, что с Овидием? Разве это не идеальный пример того, как поэт или писатель понес наказание за «идеологические» расхождения с политическим лидером? Но и в этом случае перед нами снова перенесение на августовское общество более поздних представлений. Парадоксальным образом - по крайней мере, если исходить из сконструированного в основном уже в новейшее время образа Овидия как идеологического диссидента - во многих отношениях Овидий как раз является чистейшим порождением августовского века, каков он есть. Рожденный на поколение позже, чем другие великие августовские поэты, он радуется своему времени, не будучи обремененным памятью о тех беспорядке и хаосе, которые этому времени предшествовали (A. A. 3.121-122):

prisca iuvent alios, ego me nunc denique natum gratulor: haec aetas moribus apta meis.

\footnotetext{
${ }^{20}$ См. подробный и вдумчивый анализ В. Пёшля: [Pöschl 1961].

${ }^{21}$ См. [White 1993], особенно с. 27-47; ср. его замечания о римском патронате [Ibid.: $270-271]$.

22 Ясное обсуждение проблемы см. в [Rogers 1959].
} 
Древности пусть нравятся другим — я радуюсь тому, что я родился только сейчас: эта эпоха подходит для моих нравов.

Овидий - это (иногда даже в большей степени, чем другие поэты и Ливий) такой «идеальный зритель», если позаимствовать термин из изучения греческой драмы ${ }^{23}$. Только у него одного из всей этой плеяды даты жизни охватывают всю протяженность правления Августа. Какой аспект правления Августа был центральным? Изменение, причем в невероятно большом количестве отношений: Рим и провинции, искусство и архитектура, религия, управление и гораздо больше, чем просто управление, - здесь можно сослаться на принадлежащую Эндрю Уоллес-Хэдриллу концепцию августовской культурной революции [Wallace-Hadrill 2005; 2008]. Отсюда и название овидиевского шедевра: «Метаморфозы» ${ }^{24}$. Сегодня, спустя примерно 2000 лет, мы можем отчетливее очертить перемены, произошедшие в августовском мире, его обществе и его культуре, но большинство римлян осознавало уже тогда, что происходят перемены: не просто возвращение в прошлое, но начало пути в некое, часто непонятное, будущее. В большей части своих поэтических произведений, т. е. в первую очередь в «Науке любви», «Метаморфозах» и «Фастах», Овидий с ловкостью оперирует темами и проблемами своего времени. Несомненно, он пишет, что ему заблагорассудится. Стало ли это причиной изгнания? Как известно, две причины, которые он сам называет, — это carmen et error «песня и ошибка», причем Овидий сам дает понять, что первая (т. е. поэма «Наука любви», опубликованная за восемь лет до изгнания) была только предлогом или, как сейчас бы сказали, «фейковой новостью». Что касается error'a, Овидий, которому вообще не свойственно лезть за словом в карман, необычным образом не говорит о нем вообще ничего; отсюда видно, что в этом и была реальная проблема — возможно, поэт преступил дозволенное с кем-то из семьи Августа ${ }^{25}$.

Остается задать финальный вопрос. Имел бы место подобный литературный расцвет, была бы эпоха столь же продуктивной в творческом отношении, если бы не было феномена Августа и порожденных им вопросов? Возможно, да, но тогда этот расцвет был бы совсем иным. Можно провести параллель с Афинами V в. до н. э. (а августовский Рим во многих отношениях оглядывался на Афины V в.) $)^{26}$. Угроза уничтожения во время нашествия персов, успешная борьба против них, последовавший в результате период стабильности и пришедший вслед за ним новый кризис спровоцировали то интенсивное осмысление и обсуждение базовых ценностей и идентичности, которое мы находим в афинской трагедии (а также в афинском изобразительном искусстве и архитектуре). То же самое произошло и с августовским Римом: длительный период гражданских войн довел Рим до грани самоуничтожения и спровоцировал

${ }^{23}$ Идеальный пример - это его описание Форума Августа (пусть даже подразумевается, что это взгляд на форум глазами Марса), Fast. 5.550-578.

${ }^{24}$ Более подробную аргументацию см. в [Galinsky 1999]. Ср. тему сборника статей [Luciani 2016] и название статьи [Wallace-Hadrill 2005].

${ }^{25}$ Стандартной сводной работой по этой теме остается [Thibault 1964].

${ }^{26}$ См., например, резюме докладов, представленных в 1993 г. на совместном коллоквиуме Американского института археологии и Американской филологической ассоциации «Афины и августовский Рим», в American Journal of Archaeology (Vol. 98. 1994. P. 301-303). 
поиски ответов на вопросы о римских традициях и римской идентичности. Как и в Афинах, стабильность вернулась, но для поколения Вергилия, Горация и Ливия она не была данностью. Что видно по их реакциям, а также по реакциям Овидия и других, например элегиков, так это то, что (опять же в некотором отношении это похоже на Афины V в. до н. э.) процесс оформления их литературных откликов был автономным. Схожим образом с тем, что Пауль Цанкер показал в своей фундаментальной книге применительно к августовскому изобразительному искусству, формирование литературных реакций на эпоху было не результатом спущенной сверху идеологии или пропаганды, а скорее процессом взаимного обмена и взаимодействия множества мнений [Zanker 1987]. Темы, включая самого Августа, были богатыми и многослойными, и именно соответствующая разработка их писателями сделала августовскую эпоху одной из великих эпох мировой литературы.

\section{Пер. с англ. М. В. Шумилина}

\section{Литература}

Assman 2007 — Assmann A. Geschichte im Gedächtnis. München: C. H. Beck, 2007.

Bahti 1986 - Bahti T. Ambiguity and indeterminacy: The juncture // Comparative Literature. Vol. 38. No. 3. 1986. P. 209-223.

Beard et al. 1998 - Beard M., North J., Price S. Religions of Rome. 2 vols. Cambridge: Cambridge Univ. Press, 1998.

Cooley 2009 - Cooley A. E. Res Gestae Divi Augusti: Text, Translation, and Commentary. Cambridge: Cambridge Univ. Press, 2009.

Eagleton 1994 - Eagleton T. Ideology. London; New York: Longman, 1994.

Erll, Nünning 2010 - Cultural memory studies: An international and interdisciplinary handbook / Ed. by A. Erll, A. Nünning. Berlin; Boston: De Gruyter, 2010.

Gagé 1930 - Gagé J. Romulus-Augustus // Mélanges de l’École française de Rome. Vol. 47. 1930. P. $138-181$.

Galinsky 1992 - Galinsky K. Venus, polysemy, and the Ara Pacis Augustae // American Journal of Archaeology. Vol. 96. No. 3. 1992. P. 457-475.

Galinsky 1996 - Galinsky K. Augustan culture. An interpretive introduction. Princeton: Princeton Univ. Press, 1996.

Galinsky 1999 - Galinsky K. Ovid's Metamorphoses and Augustan cultural thematics // Ovidian transformations. Essays on Ovid's Metamorphoses and its reception / Ed. by P. Hardie et al. Cambridge: Cambridge Philological Society, 1999. P. 103-111.

Galinsky 2012 - Galinsky K. Augustus. Introduction to the life of an emperor. Cambridge: Cambridge Univ. Press, 2012.

Galinsky 2013 - Galinsky K. La costruzione del mito augusteo: Some construction elements // La costruzione del mito augusteo / Ed. by M. Labate, G. Rosati. Heidelberg: Winter, 2013. P. 29-47.

Galinsky 2016a - Memory in ancient Rome and early Christianity / Ed. by K. Galinsky. Oxford: Oxford Univ. Press, 2016.

Galinsky 2016b - Galinsky K. Memory and forgetting in the age of Augustus. The 2014 Todd Memorial Lecture. Sydney: Univ. of Sydney, 2016. 
Geiger 2008 - Geiger J. The first hall of fame: A study of the statues in the Forum Augustum. Leiden: Brill, 2008.

Georgii 1905-1906 — Tiberi Claudi Donati ad Tiberium Claudium Maximum Domitianum filium suum Interpretationes Vergilianae / Ed. by H. Georgii. Vols. 1-2. Leipzig: Teubner, 1905-1906.

Gowing 2005 - Gowing A. Empire and memory. The representation of the Roman Republic in imperial culture. Cambridge: Cambridge Univ. Press, 2005.

Gowing 2016 - Gowing A. Memory as motive in Tacitus // Memory in ancient Rome and early Christianity / Ed. by K. Galinsky. Oxford: Oxford Univ. Press, 2016. P. 43-64.

Graves 1962 - Graves R. The Virgil cult // Virginia Quarterly Review. Vol. 38. № 1. 1962. P. 13-32.

Hoff von den et al. 2014 - Hoff von den R., Stroh W., Zimmermann M. Divus Augustus. Der erste römische Kaiser und seine Welt. München: Beck, 2014.

Jaeger 1997 - Jaeger M. Livy’s Written Rome. Ann Arbor: The Univ. of Michigan Press, 1997.

Jauss 1977 - Jauss H. R. Ästhetische Erfahrung und Literarische Hermeneutik. München: Fink, 1977.

Kennedy 1992 - Kennedy D. F. 'Augustan' and 'anti-Augustan': Reflections on terms of reference // Roman poetry and propaganda in the age of Augustus / Ed. by A. Powell. Bristol: Bristol Classical Press, 1992. P. 26-58.

Little 1982 - Little D. Politics in Augustan poetry // Aufstieg und Niedergang der römischen Welt. Teil 2. Bd. 30. Teilbd. 1 / Hrsg. W. Haase. Berlin: De Gruyter, 1982. S. 254-370.

Luce 1990 - Luce T. J. Livy, Augustus, and the Forum Augustum // Between Republic and Empire: Interpretations of Augustus and his Principate / Ed. by K. Raaflaub, M. Toher. Berkeley; Los Angeles: Univ. of California Press, 1990. P. 123-138.

Luciani 2016 - Entre mots et marbre. Les métamorphoses d'Auguste / Ed. by S. Luciani. Bordeaux: Ausonius, 2016.

Lyne 1987 - Lyne R. O. A. M. Further voices in Vergil's Aeneid. Oxford: Oxford Univ. Press, 1987.

Nisbet, Hubbard 1970 - Nisbet R. G. M., Hubbard M. A commentary on Horace: Odes, book 1. Oxford: Clarendon Press, 1970.

Norden 1970 - Norden E. P. Vergilius Maro Aeneis Buch VI. 5. Ausg. Darmstadt: Wissenschaftliche Buchgesellschaft, 1970.

Parry 1963 - Parry A. The two voices in Virgil's Aeneid // Arion. Vol. 2. No. 4. 1963. P. 66-80.

Pethes, Ruchatz 2001 — Gedächtnis und Erinnerung: ein interdisziplinäres Lexikon / Ed. by N. Pethes, J. Ruchatz. Reinbek: Rowohlt, 2001.

Pöschl 1961 - Pöschl V. Die große Maecenasode des Horaz (c. 3,29). Heidelberg: Winter, 1961.

Powell 1992 - Roman poetry and propaganda in the age of Augustus / Ed. by A. Powell. Bristol: Bristol Classical Press, 1992.

Putnam 1965 - Putnam M. The poetry of the Aeneid: Four studies in imaginative unity and design. Cambridge, MA: Harvard Univ. Press, 1965.

Raaflaub, Toher 1990 - Between Republic and Empire: Interpretations of Augustus and his Principate / Ed. by K. Raaflaub, M. Toher. Berkeley; Los Angeles: Univ. of California Press, 1990.

Rich, Williams 1999 - Rich J., Williams J. H. C. Leges et iura P.R. restituit: a new aureus of Octavian and the settlement of 28-27 B. C. // Numismatic Chronicle. Vol. 159. 1999. P. 169-213.

Rogers 1959 - Rogers R. S. The emperor's displeasure — "amicitiam renuntiare" // Transactions and Proceedings of the American Philological Association. Vol. 90. 1959. P. 224-237. 
Schauer 2007 - Schauer M. Aeneas dux in Vergils Aeneis. Eine literarische Fiktion in augusteischer Zeit. München: C. H. Beck, 2007.

Scheid 2007 - Scheid J. Res Gestae Divi Augusti. Hauts faits du divin Auguste. Paris: Belles Lettres, 2007.

Seider 2013 - Seider A. Memory in Vergil's Aeneid: Creating the past. Cambridge: Cambridge Univ. Press, 2013.

Swan 2004 - Swan P. M. The Augustan succession: An historical commentary on Cassius Dio's Roman History, Books 55-56 (9 B. C. - A. D. 14). New York: Oxford Univ. Press, 2004.

Syme 1939 - Syme R. The Roman revolution. Oxford: Clarendon Press, 1939.

Thibault 1964 - Thibault $J$. The mystery of Ovid's exile. Berkeley; Los Angeles: Univ. of California Press, 1964.

Thomas 1988 - Virgil, Georgics. Vol. 2: Books III-IV / Ed. by R. F. Thomas. Cambridge: Cambridge Univ. Press, 1988.

Torelli 1992 - Torelli M. Typology and structure of Roman historical reliefs. Ann Arbor: The Univ. of Michigan Press, 1992.

Trillmich 1988 - Trillmich W. Münzpropaganda // Kaiser Augustus und die verlorene Republik / Ed. by W.-D. Heilmeyer et al. Berlin: Mann, 1988. S. 474-491.

Wallace-Hadrill 2005 - Wallace-Hadrill A. Mutatas Formas: The Augustan transformation of Roman knowledge // The Cambridge companion to the age of Augustus / Ed. by K. Galinsky. Cambridge: Cambridge Univ. Press, 2005. P. 55-84.

Wallace-Hadrill 2008 - Wallace-Hadrill A. Rome's cultural revolution. Cambridge: Cambridge Univ. Press, 2008.

Wardle 2014 - Wardle D. Suetonius. Life of Augustus. Oxford: Oxford Univ. Press, 2014.

Weinbrot 1978 - Weinbrot H. Augustus Caesar in "Augustan" England: The decline of a classical norm. Princeton: Princeton Univ. Press, 1978.

White 1993 - White P. Promised verse. Poets in the society of Augustan Rome. Cambridge, MA: Harvard Univ. Press, 1993.

Woodman, West 1984 - Poetry and politics in the age of Augustus / Ed. by T. Woodman, D. West. Cambridge: Cambridge Univ. Press, 1984.

Zanker 1987 - Zanker P. Augustus und die Macht der Bilder. München: C. H. Beck, 1987.

\title{
Augustan literature and Augustan 'ideology': AN ONGOING REASSESSMENT
}

\author{
Galinsky, Karl \\ PhD \\ Cailloux Centennial Professor, \\ Department of Classics, University of Texas at Austin \\ 110 Inner Campus Drive, Austin, TX 78705, USA \\ Tel.: +1 (512) 471-85-04, +1 (512) 471-57-42 \\ E-mail: galinsky@austin.utexas.edu
}

Abstract. For the topic of "Literature and Politics in Antiquity" the Augustan period, and especially the relationship of Augustus and the poets, has become a paradigm. This paper surveys and critiques the main trends of changing assessments, and the reasons for them, from antiquity to the present. I follow Peter White's foundational demonstration that the "political" interpretation of 
Augustan poetry is an anachronistic imposition; further, I briefly examine the imprecision of the notion of "ideology". By analysis of some representative examples, such as Horace's Ode 1.2, I develop what is a more accurate notion, i.e. that of a national discourse or conversation with many participants besides Augustus with many different perspectives. While Syme's model of "the organization of opinion" has been largely discarded, binary models have proved too simplistic and have increasingly given way to more dynamic approaches, which are also more firmly grounded in the actual realities of the time, including the intentional polysemy of works of art. Another interpretive issue is the projection of the present into the past, which has been highlighted anew in studies of cultural and historical memory.

Keywords: Augustan literature, politics and literature, ideology, presentism, interpretation - contingencies, Tiberius Claudius Donatus, Augustanism, polysemy, Horace, Vergil, Livy, Ovid

\section{References}

Assmann, A. (2007). Geschichte im Gedächtnis. Munich: C. H. Beck. (In German).

Bahti, T. (1986). Ambiguity and indeterminacy: The juncture. Comparative Literature, 38(3), 209-223.

Beard, M., North, J., Price, S. (1998). Religions of Rome (2 Vols.). Cambridge: Cambridge Univ. Press.

Cooley, A. E. (2009). Res gestae Divi Augusti: Text, translation, and commentary. Cambridge: Cambridge Univ. Press.

Eagleton, T. (1994). Ideology. London; New York: Longman.

Erll, A., Nünning, A. (Eds.) (2010). Cultural memory studies; An international and interdisciplinary handbook. Berlin; Boston: De Gruyter.

Gagé, J. (1930). Romulus-Augustus. Mélanges de l'École française de Rome, 47, 138-181.

Galinsky, K. (1992). Venus, polysemy, and the Ara Pacis Augustae. American Journal of Archaeology 96(3), 457-475.

Galinsky, K. (1996). Augustan culture. An interpretive introduction. Princeton: Princeton Univ. Press.

Galinsky, K. (1999). Ovid's Metamorphoses and Augustan cultural thematics. In P. Hardie et al. (Eds.). Ovidian transformations. Essays on Ovid's Metamorphoses and its reception, 103-111. Cambridge: Cambridge Philological Society.

Galinsky, K. (2012). Augustus. Introduction to the life of an emperor. Cambridge: Cambridge Univ. Press.

Galinsky, K. (2013). La costruzione del mito augusteo: Some construction elements. In M. Labate, G. Rosati (Eds.). La costruzione del mito augusteo, 29-47. Heidelberg: Winter.

Galinsky, K. (Ed.) (2016a). Memory in ancient Rome and early Christianity. Oxford: Oxford Univ. Press.

Galinsky, K. (2016b). Memory and forgetting in the age of Augustus. The 2014 Todd Memorial Lecture. Sydney: University of Sydney.

Geiger, J. (2008). The first hall of fame: A study of the statues in the Forum Augustum. Leiden: Brill. 
Georgii, H. (Ed.). (1905-1906). Tiberi Claudi Donati ad Tiberium Claudium Maximum Domitianum filium suum Interpretationes Vergilianae (Vols. 1-2). Leipzig: Teubner. (In Latin).

Gowing, A. (2005). Empire and memory. The representation of the Roman Republic in imperial culture. Cambridge: Cambridge Univ. Press.

Gowing, A. (2016). Memory as motive in Tacitus. In K. Galinsky (Ed.). Memory in ancient Rome and early Christianity, 43-64. Oxford: Oxford Univ. Press.

Graves, R. (1962). The Virgil Cult. Virginia Quarterly Review, 38(1), 13-32.

Hoff von den, R., Stroh, W., Zimmermann, M. (2014). Divus Augustus. Der erste römische Kaiser und seine Welt. Munich: Beck. (In German).

Jaeger, M. (1997). Livy's written Rome. Ann Arbor: The Univ. of Michigan Press.

Jauss, H. R. (1977). Ästhetische Erfahrung und Literarische Hermeneutik. Munich: Fink. (In German).

Kennedy, D. F. (1992). 'Augustan' and 'anti-Augustan': Reflections on terms of reference. In A. Powell (Ed.). Roman poetry and propaganda in the age of Augustus, 26-58. Bristol: Bristol Classical Press.

Little, D. (1982). Politics in Augustan poetry. In W. Haase (Ed.). Aufstieg und Niedergang der römischen Welt, (Vol. 2.30.1), 254-370. (In German).

Luce, T. J. (1990). Livy, Augustus, and the Forum Augustum. In K. Raaflaub, M. Toher (Eds.). Between Republic and Empire: Interpretations of Augustus and his Principate, 123-138. Berkeley; Los Angeles: Univ. of California Press.

Luciani, S. (Ed.) (2016). Entre mots et marbre. Les métamorphoses d'Auguste. Bordeaux: Ausonius. (In French).

Lyne, R. O. A. M. (1987). Further voices in Vergil's Aeneid. Oxford: Oxford Univ. Press.

Nisbet, R. G. M., Hubbard, M. (1970). A commentary on Horace: Odes, Book 1. Oxford: Clarendon Press.

Norden, E. (1970). P. Vergilius Maro Aeneis Buch VI. (5 ${ }^{\text {th }}$ ed.). Darmstadt: Wissenschaftliche Buchgesellschaft. (In German).

Parry, A. (1963). The two voices of Virgil's Aeneid. Arion, 2(4), 66-80.

Pethes, N., Ruchatz, J. (Eds.) (2001). Gedächtnis und Erinnerung: ein interdisziplinäres Lexikon. Reinbek: Rowohlt. (In German).

Pöschl, V. (1961). Die große Maecenasode des Horaz (c. 3,29). Heidelberg: Winter. (In German).

Powell, A. (Ed.) (1992). Roman poetry and propaganda in the age of Augustus. Bristol: Bristol Classical Press.

Putnam, M. (1965). The poetry of the Aeneid: Four studies in imaginative unity and design. Cambridge, MA: Harvard Univ. Press.

Raaflaub, K., Toher, M. (Eds.) (1990). Between Republic and Empire: Interpretations of Augustus and his Principate. Berkeley; Los Angeles: Univ. of California Press.

Rich, J., Williams, J. H. C. (1999). Leges et iura P.R. restituit: A new aureus of Octavian and the settlement of 28-27 B. C. Numismatic Chronicle, 159, 169-213.

Rogers, R. S. (1959). The emperor's displeasure - "amicitiam renuntiare". Transactions and Proceedings of the American Philological Association, 90, 224-237.

Schauer, M. (2007). Aeneas dux in Vergils Aeneis. Eine literarische Fiktion in augusteischer Zeit. Munich: C. H. Beck. (In German).

Scheid, J. (2007). Res Gestae Divi Augusti. Hauts faits du divin Auguste. Paris: Belles Lettres. (In German).

Seider, A. (2013). Memory in Vergil's Aeneid: Creating the past. Cambridge: Cambridge Univ. Press. 
Swan, P. M. (2004). The Augustan succession: An historical commentary on Cassius Dio's Roman History, Books 55-56 (9 B. C. - A. D. 14). New York: Oxford Univ. Press.

Syme, R. (1939). The Roman revolution. Oxford: Clarendon Press.

Thibault, J. (1964). The mystery of Ovid's exile. Berkeley; Los Angeles: Univ. of California Press.

Thomas, R. F. (Ed.) (1988). Virgil, Georgics (Vol. 2: Books III-IV). Cambridge: Cambridge Univ. Press.

Torelli, M. (1992). Typology and structure of Roman historical reliefs. Ann Arbor: The Univ. of Michigan Press.

Trillmich, W. (1988). Münzpropaganda. In W.-D. Heilmeyer et al. (Eds.). Kaiser Augustus und die verlorene Republik, 474-491. Berlin: Mann. (In German).

Wallace-Hadrill, A. (2005). Mutatas Formas: The Augustan transformation of Roman knowledge. In K. Galinsky (Ed.). The Cambridge companion to the age of Augustus, 55-84. Cambridge: Cambridge Univ. Press.

Wallace-Hadrill, A. (2008). Rome's cultural revolution. Cambridge: Cambridge Univ. Press.

Wardle, D. (2014). Suetonius. Life of Augustus. Oxford: Oxford Univ. Press.

Weinbrot, H. (1978). Augustus Caesar in “Augustan” England: The decline of a classical norm. Princeton: Princeton Univ. Press.

White, P. (1993). Promised verse. Poets in the society of Augustan Rome. Cambridge, MA: Harvard Univ. Press.

Woodman, T., West, D. (Eds.) (1984). Poetry and politics in the age of Augustus. Cambridge: Cambridge Univ. Press.

Zanker, P. (1987). Augustus und die Macht der Bilder. Munich: C. H. Beck. (In German).

To cite this article:

Galinsky, K. (2017). Avgustovskaia literatura i avgustovskaia "ideologita": PERESMOTR otSENOK [Augustan literature and Augustan 'IDeOlogy': An ongoing reassessment]. Trans. by M. V. Shumilin. Shagi / Steps, 3(4), $151-$ 167. (In Russian). 